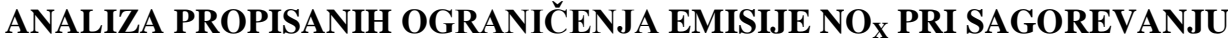 BIOMASE U ODABRANIM EVROPSKIM ZEMLJAMA I U SRBIJI
}

\section{ANALYSIS OF PRESCRIPED LIMITS OF NOx EMISSIONS FROM BIOMASS COMBUSTION IN SELECTED EUROPEAN COUNTRIES AND IN SERBIA}

\author{
Milica Mladenović, Stevan Nemoda, Milijana Paprika, \\ Ana Marinković,' Branislav Repić \\ Univerzitet u Beogradu, Institut za nuklearne nauke "Vinča",
} Laboratorija za termotehniku i energetiku, 11351 Beograd, Mihaila Petrovića Alasa 12-14 Email: $\underline{\text { mica@vinca.rs }}$

\section{SAŽETAK}

Usklađivanje potreba očuvanja životne sredine i rastućih energetskih potreba savremenog društva promoviše primenu biomase kao zamene za fosilna goriva i održivu opciju za ublažavanje emisije gasova staklene bašte. Pored niza prednosti upotrebe iste $u$ energetske svrhe, postoje i izvesni nedostaci, od kojih je i moguća relativno visoka emisija NOx prilikom sagorevanje biomase. Kontrola emisije oksida NOx, emitovanih u procesu sagorevanja biomase, postaje sve značajniji tehnički izazov zbog uvođenja sve striktnijih granica emisije. U radu je dat pregled i analiza domaćih normi vezanih za emisiju NOx, kao i zakonskih normi i iskustva nekih od odabranih evropskih zemalja. Preporučuje se da se u domaćim propisima, koji se odnose na emisiju NOx, posebno definišu granice u slučaju sagorevanja agro biomase, zbog njene izražene dostupnosti i visokog sadržaja azota.

Ključne reči: Biomasa, sagorevanje, NOx emisija, analiza.

\section{UVOD}

Biomasa se smatra ekonomski i ekološki prihvatljivom za sagorevanje, jer je $\mathrm{CO}_{2}$ neutralna i emisija zagađivača iz biomase je manje izražena u odnosu na sagorevanje uglja. Poznavanje emisije pojedinih opasnih materija iz sagorevanja biomase, njenih ekoloških i zdravstvenih efekata, kao i razumevanje kako da se ona minimizira je od suštinskog značaja. Emisija azotnih oksida (NOx) je jedan od najvažnijih izazova u ovoj oblasti. Azotni oksidi igraju značajnu ulogu u problemima zagađenja. Među sedam različitih oksida azota identifikovanih u atmosferi, azot oksid (NO) i azot dioksid $\left(\mathrm{NO}_{2}\right)$ su najdominantniji zagađivači. Preko $90 \%$ oksida azota emitovanih usled procesa sagorevanja čini $\mathrm{NO}$, dok ostatak čine $\mathrm{NO}_{2}$ i $\mathrm{N}_{2} \mathrm{O}$, pri čemu su količine $\mathrm{N}_{2} \mathrm{O}$ zanemarljive u odnosu na $\mathrm{NO}$ i $\mathrm{NO}_{2}$, pa zakonska ograničenja ne postoje za njegovu emisiju. NO se u atmosferi konvertuje u $\mathrm{NO}_{2}$ pa propisi iz oblasti zaštite životne sredine tretiraju sve okside azota kao $\mathrm{NO}_{2}$. 
Pored toga što je izbor tehnologije sagorevanje biomase i deNOx sistema zasnovan na ekonomskim, tehničkim i lokalnim preduslovima, takođe u velikoj meri zavisi i od važećih zakonskih ograničenja koja se tiču zaštite životne sredine. Maksimalne vrednosti dozvoljene emisije (GVE-granične vrednosti emisije) za članice EU značajno variraju između zemalja što utiče na izbor tehnologije sagorevanja biomase. Potrebno je istaći da dozvoljene GVE iz stacionarnih izvora su različito definisane za postojeća i za nove $\mathrm{i} /$ ili postojeća ali značajno konstrukciono promenjena postrojenja u EU. Što se tiče poređenja GVE u zemljama EU i SAD, to nije moguće jer su one definisane različito. Za članice EU GVE su ustanovljene shodno propisima koji proističu iz Large Combustion Plants (LCP) (2001/80/EG, PB L 309) [1], kao i Waste Incineration Directive (WID) (2000/76/EG, PB L 332) [2]. Pri tome se 2001/80/EG primenjuje za biomasu koja se definiše kao produkt agrarne proizvodnje i šumarstva, otpad iz povrtarske proizvodnje, otpad iz drvno-prerađivačke i prehrambene industrije, netretiran drvni i otpad od kore, plute. Guideline [2] se primenjuje na sav otpad. Vrednosti GVE prema ovim dokumentima dati su u Tab. 1 .

Tab. 1. Pregled granica NOx emisije prema LCP i WID $\left(\mathrm{mg} / \mathrm{m}^{3}\right)$ za čvrstu biomasu Tab. 1. Review the limits NOx emissions to the LCP and WID $\left(\mathrm{mg} / \mathrm{m}^{3}\right)$ for solid biomass

\begin{tabular}{|c|c|c|c|c|c|c|c|c|c|}
\hline & \multicolumn{4}{|c|}{ LCP (clean biomass) } & \multicolumn{5}{|c|}{ Waste Incineration Directive } \\
\hline & \multicolumn{4}{|c|}{ b } & \multirow{2}{*}{\multicolumn{2}{|c|}{$\begin{array}{l}\mathrm{a} \\
11\end{array}$}} & \multicolumn{3}{|c|}{$\mathrm{b}$} \\
\hline $\mathrm{O}_{2 \text { ref }}, \%$ & \multicolumn{4}{|c|}{6} & & & \multicolumn{3}{|c|}{6} \\
\hline $\mathrm{MW}_{\text {th }}$ & $\geq 50$ & $\begin{array}{l}50- \\
100\end{array}$ & $\begin{array}{l}100- \\
300\end{array}$ & $>300$ & $<6 \mathrm{t} / \mathrm{h}$ & $\geq 6 \mathrm{t} / \mathrm{h}$ & $\begin{array}{l}50- \\
100\end{array}$ & $100-300$ & $>300$ \\
\hline $\begin{array}{l}\mathrm{NOx}, \\
\mathrm{mg} / \mathrm{m}^{3}\end{array}$ & 200 & 400 & 300 & 200 & 200 & 400 & 350 & $\begin{array}{c}300(350 \\
\text { za FB) }\end{array}$ & 300 \\
\hline
\end{tabular}

a - kosagorevanje/cocombustion; b - samostalno sagorevanje/individual combustion

\section{ANALIZA GRANIČNIH EMISIJA NOx U SVETU}

$\mathrm{U}$ ovom poglavlju biće predstavljene dozvoljene granice emisije $\mathrm{NO}_{\mathrm{x}} \mathrm{u}$ odabranim Evropskim zemljama radi poređenja sa normama koje važe u Republici Srbiji.

\subsection{Austrija}

Dozvoljena emisija NOx za stambene grejne kotlove na čvrstu biomasu nominalne snage do $300 \mathrm{~kW}$, za ručno i automatsko doziranje goriva iznosi 150 $\mathrm{mg} / \mathrm{MJ}_{\mathrm{LCV}}$. Dozvoljene emisije NOx $\left(\mathrm{mg} / \mathrm{m}_{0}^{3}\right.$, ref. $\left.13 \% \mathrm{O}_{2}\right)$ za parne (STB) i vrelovodne kotlove (HWB) u industrijskim i komercijalnim postrojenjima date su u Tab. 2. 
Tab. 2. Dozvoljene emisije za parne (STB) i vrelovodne kotlove (HWB)

Tab. 2. The permitted emissions for steam (STB) and hot water boilers (HWB)

\begin{tabular}{|c|l|c|c|c|}
\hline $\begin{array}{l}\text { Nominalna snaga } \\
\text { Nominal power }\end{array}$ & STB & \multicolumn{3}{|c|}{ HWB } \\
\hline MW & & $\begin{array}{c}\text { Drvo } \\
\text { Wood }\end{array}$ & $\begin{array}{c}\text { Drvni ostaci } \\
\text { Wood residues }\end{array}$ & $\begin{array}{c}\text { Kontaminirani drvni ostaci } \\
\text { Contaminated wood residues }\end{array}$ \\
\hline $0.15-5$ & - & 250 & 300 & 500 \\
\hline $5-10$ & - & 250 & 300 & 350 \\
\hline $10-50$ & - & 200 & 200 & 350 \\
\hline $50-300$ & 300 & 200 & 200 & 350 \\
\hline$>300$ & 200 & 200 & 200 & 350 \\
\hline
\end{tabular}

\subsection{Danska}

Preporuke za GVE su date u nacionalnim smernicama [3,4], a usvojene granice su u skladu sa saglašnošću lokalnih zajednica o uticaju postrojenja na životnu sredinu. Dozvoljene emisije NOx za postrojenja nominalne snage $>5 \mathrm{MW}$, za drvo, drvni pelet, piljevinu, drvnu sečku, zrnastu biomasu, slamu i dr. iznosi $300\left(\mathrm{mg} / \mathrm{m}^{3}{ }_{0}\right.$,ref. $\left.10 \% \mathrm{O}_{2}\right)$.

\subsection{Finska}

Opšta ograničenja NOx emisije za biogoriva (drvo, drvni otpad, treset, slama) su prikazani u Tab. 3, s tim što lokalne vlasti mogu postaviti strožija ograničenja emisije.

Tab. 3. Dozvoljene emisije NOx u Finskoj

Tab. 3. NOx emissions permitted in Finland

\begin{tabular}{|c|c|}
\hline Proizvedena toplota/Produced heat, $\mathrm{MW}$ & $\mathrm{NOx}, \mathrm{mg} / \mathrm{m}^{3}{ }_{0}$, ref. $6 \% \mathrm{O}_{2}$ \\
\hline $50-100$ & 400 \\
\hline $100-300$ & 300 \\
\hline$\geq 300$ & 150 \\
\hline
\end{tabular}




\subsection{Nemačka}

Važeća ograničenja emisije za goriva su prikazani u Tab. 4.

Tab. 4. Dozvoljene emisije NOx u Nemačkoj

Tab. 4. NOx emissions permitted in Germany

\begin{tabular}{|c|c|c|}
\hline $\begin{array}{c}\text { Izvor } \\
\text { Reference }\end{array}$ & $\begin{array}{l}\text { Nominalni kapacitet } \\
\text { Nominal power, MW }\end{array}$ & $\begin{array}{c}\mathrm{NOx} \\
\mathrm{mg} / \mathrm{m}^{3}\end{array}$ \\
\hline Slama i sl./Straw at sim. $\left(\right.$ ref. $\left.13 \% \mathrm{O}_{2}\right)$ 1.BImSchV [5] & $<0.1$ & - \\
\hline \multirow{2}{*}{$\begin{array}{l}\text { Slama i slično } \\
\left.\text { Straw at similar, (ref. } 11 \% \mathrm{O}_{2}\right) \text { TA-Luft 5.4.1.3 [6] }\end{array}$} & $0,1-1$ & 500 \\
\hline & $1-50$ & 400 \\
\hline \multirow{3}{*}{ 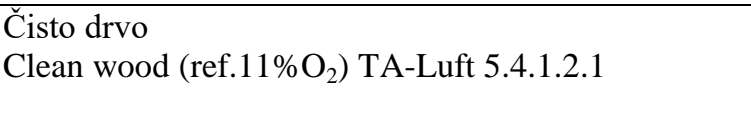 } & $1-2.5$ & 250 \\
\hline & $2.5-5$ & 250 \\
\hline & $5-50$ & 250 \\
\hline Čisto drvo/Clean wood, $\left(\right.$ ref.13\% $\mathrm{O}_{2}$ ) 1.BImSchV & $0.015-1$ & - \\
\hline $\begin{array}{l}\text { Korišćeno drvo, lako kontaminirano } \\
\left.\text { Used wood little contamin., (ref.13\% } \mathrm{O}_{2}\right) \text { 1.BImSchV }\end{array}$ & $0.05-1$ & - \\
\hline $\begin{array}{l}\text { Korišćeno drvo, lako kontaminirano } \\
\text { Used wood little cont (ref.11\% } \mathrm{O}_{2} \text { ) TA-Luft 5.4.1.2.1 }\end{array}$ & $1-50$ & 400 \\
\hline $\begin{array}{l}\text { Korišćeno drvo, teško kontaminirano } \\
\text { Used wood much contam. }\left(\text { ref. } 11 \% \mathrm{O}_{2}\right) 17 . \mathrm{BImSchV}\end{array}$ & $\begin{array}{l}\text { Sve } \\
\text { All }\end{array}$ & 200 \\
\hline
\end{tabular}

\subsection{Holandija}

Pri definiciji granica NOx emisije (Tab. 5) holandsko zakonodavstvo pravi razliku imeđu čiste biomase (kao što je definisano u evropskom LCP) i sve druge vrste biomase, koja se tretira kao otpad (WID). Opšte smernice koja se legislativa primenjuje su sledeće:

a) Za sagorevanje ili ko-sagorevanje čiste čvrste biomase iz poljoprivrede, šumarstva i operacije održavanja pejzaža kao što je definisano u Evropskoj LCP direktivi (kao što čisto drvo, pokošena trava, ostaci od kompostiranja, itd), primenjuje se takozvani BEESA.

b) Za sva ostala čvrsta goriva na bazi biomase, primenjuje se BVA (izvedeno iz Evropske WID direktive). Ovo se odnosi na ostatke prerade povrća, voća i baštenski otpad, pomije, životinjski stajnjak, mešoviti industrijski otpad, itd.

c) BEES-B važi za gasovita goriva proizvedena iz anaerobne digestije ili toplotnom gasifikacijom biomase koja sagorevaju u gasnom motoru.

d) Izuzetak je napravljen za sagorevanja otpada u vidu čistog drveta u industrijskoj instalaciji manjoj od 5MWth u vlasništvu proizvođača drvne građe. U takvim slučajevima se primenjuje NER-BR za otpadno čisto drvo. 
Tab. 5. Definisane granice NOx emisije u Holandiji [7]

Tab. 5. The defined boundaries of NOx emissions in the Netherlands [7]

\begin{tabular}{|c|c|c|}
\hline $\begin{array}{c}\text { Izvor } \\
\text { Reference }\end{array}$ & $\begin{array}{l}\text { Snaga } \\
\text { Power }\end{array}$ & $\begin{array}{c}\mathrm{NOx} \\
\mathrm{mg} / \mathrm{m}_{0}^{3}\end{array}$ \\
\hline \multirow{2}{*}{$\begin{array}{l}\text { BEES-A: Čista čvrsta biomasa } \\
\text { Clean solid biomass, } 6 \% \mathrm{O}_{2 \mathrm{dry}}\end{array}$} & $<300 \mathrm{MW}_{\text {th }}$ & 100 \\
\hline & $>300 \mathrm{MW}_{\text {th }}$ & 200 \\
\hline $\begin{array}{l}\text { NER: Čisto otpadno drvo } \\
\text { Clean waste wood, } 11 \% \mathrm{O}_{2 \mathrm{dry}}\end{array}$ & $>250 \mathrm{MW}_{\text {th }}$ & 400 \\
\hline \multirow{2}{*}{$\begin{array}{l}\text { BVA: Sagorevanje kontaminirane čvrste biomase } \\
\text { Combustion of contamined solid biomass, } 11 \% \mathrm{O}_{2 \mathrm{dry}}\end{array}$} & $\eta_{\text {el.eq }}>40 \%,<20 \mathrm{MW}_{\text {th }}$ & 130 \\
\hline & Ostalo/others & 70 \\
\hline \multirow{2}{*}{$\begin{array}{l}\text { BVA: Kosagorevanje kontaminirane čvrste biomase } \\
\text { Cocombustion of contamined solid biomas, } 11 \% \mathrm{O}_{2 \mathrm{dry}}\end{array}$} & $<300 \mathrm{MW}_{\mathrm{th}}$ & 100 \\
\hline & $>300 \mathrm{MW}_{\text {th }}$ & 200 \\
\hline
\end{tabular}

\subsection{Belgija}

U francuskom govornom delu Belgije, Valoniji, granice emisije su definisane građevinskom dozvolom kako ne postoje zvanična opšta ograničenja emisije. Vrednosti u tabeli su uglavnom one prema kojima lokalni organi vlasti odobravaju građevinske dozvole. Vrednosti date u Tab. 6 se odnose na postrojenja za čisto drvo i referentni $\mathrm{O}_{2}$ od $11 \%$.

Tab. 6. Definisane granice NOx emisije $\left(\mathrm{mg} / \mathrm{m}^{3}{ }_{\mathrm{o}}\right.$, ref. $\left.11 \% \mathrm{O}_{2}\right)$ u Belgiji

Tab. 6. Defined limits of NOx emissions $\left(\mathrm{mg} / \mathrm{m}^{3}{ }_{0}\right.$, ref. $\left.11 \% \mathrm{O} 2\right)$ in Belgium

\begin{tabular}{|c|c|c|}
\hline $\begin{array}{c}\text { Proizvedena toplota } \\
\text { Produced heat, } \mathrm{MW}_{\text {th }}\end{array}$ & $\begin{array}{c}\text { Postojeća postrojenja } \\
\text { Existing plants }\end{array}$ & $\begin{array}{c}\text { Nova postrojenja } \\
\text { New plants }\end{array}$ \\
\hline $0.5-1$ & 500 & 500 \\
\hline $1-5$ & 500 & 250 \\
\hline $5-50$ & 400 & 250 \\
\hline
\end{tabular}

\subsection{Norveška}

Za instalacije za sagorevanje koji prelaze oko $5 \mathrm{MW}$ izdaju se pojedinačne dozvole. Stepen specifikacije ograničenja emisije variraju zavisno od tipa goriva, veličine postrojenja i datuma izdavanja licence. Novije licence koje regulišu emisiju su preciznije i rigoroznije nego starije. Broj izdatih dozvola sa specifičnim ograničenjima emisije nije dostupna. Instalacije za sagorevanje obuhvaćene direktivom za integrisano sprečavanje i ontrolu zagađivanja životne sredine (IPPC) [8] se generalno regulišu na osnovu najboljih raspoloživih tehnologija (BAT - The Best Available Techniques). Sledeća ograničenja emisije su indikatori ograničenja emisije u postojećim instalacijama za sagorevanje biomase manjim od $50 \mathrm{MW}$ a koja nisu pokrivena IPPC Direktivom. Granice emisije daju smernice za tela koja izdaju dozvole, a o konačnim GVE za instalacije se odlučuje izdavanjem individualnih dozvola. U izvesnim slučajevima odobravaju se više vrednosti emisije. Stoga postojeće vrednosti granica NOx emisije (Tab. 7) su privremene; međutim, one se aktivno koriste u skladu sa Norwegian Pollution Control Authority (SFT) [9]. 
Tab. 7. Definisane granice NOx emisije $\left(\mathrm{mg} / \mathrm{m}^{3}{ }_{\mathrm{o}}\right.$, ref. $\left.11 \% \mathrm{O}_{2}\right)$ u Norveškoj

Tab. 7. Defined limits of NOx emissions $\left(\mathrm{mg} / \mathrm{m}^{3}\right.$, ref. $\left.11 \% \mathrm{O} 2\right)$ in Norway

\begin{tabular}{|c|c|c|}
\hline $\begin{array}{c}\text { Snaga } \\
\text { Power, } \text { MW }_{\text {th }}\end{array}$ & $\begin{array}{c}\text { Postojeća postrojenja } \\
\text { Existing plants }\end{array}$ & $\begin{array}{c}\text { Nova postrojenja } \\
\text { New plants }\end{array}$ \\
\hline $0.5-1$ & - & 250 \\
\hline $1-5$ & - & 250 \\
\hline $5-20$ & 300 & 200 \\
\hline $20-50$ & 300 & 200 \\
\hline
\end{tabular}

\section{8. Švedska}

Ograničenja emisije se generalno izdaju dozvolom od strane resorne vlasti.

a) $\mathrm{Za}$ male uređaje u domaćinstvu do $300 \mathrm{~kW}$, reguliše se emisija organskih gasnih jedinjenja (OGC) i ugljen monoksida (CO).

b) Za postrojenja od 300kW - 50MW Emisija azotnih oksida se u praksi ograničava preko sistema za NOx-takse, i odnosi se na postrojenja veća od 25 GWh godišnje.

c) Postrojenja veća od $50 \mathrm{MW}$. Granične vrednosti emisija date su u Tab. 8.

\section{9. Švajcarska}

Za instalacije manje od $70 \mathrm{~kW}$, granična vrednost emisije odnosi se samo na test ispitivanja i nije predmet kontrola emisija u praksi. Granična vrednost emisije NOx za postrojenja veća od $70 \mathrm{~kW}$ koje treba da budu zagarantovana u praksi i koja su planirana da se realizuju (Tab. 9).

Tab. 8. Definisane granice NOx emisije $\left(\mathrm{mg} / \mathrm{m}^{3}\right.$, ref. $\left.6 \% \mathrm{O}_{2}\right)$ u Švedskoj

Tab. 8. Defined limits of NOx emissions $\left(\mathrm{mg} / \mathrm{m}^{3}{ }_{\mathrm{o}}\right.$, ref. $\left.6 \% \mathrm{O} 2\right)$ in Sweden

\begin{tabular}{|c|c|c|}
\hline $\begin{array}{c}\text { Snaga } \\
\text { Power, } \text { MW }_{\text {th }}\end{array}$ & $\begin{array}{c}\text { Postojeća postrojenja } \\
\text { Existing plants }\end{array}$ & $\begin{array}{c}\text { Nova postrojenja } \\
\text { New plants }\end{array}$ \\
\hline $50-100$ & 600 & 400 \\
\hline $100-300$ & 600 & 300 \\
\hline $300-350$ & 600 & 200 \\
\hline $350-500$ & 600 & 200 \\
\hline$>500$ & 500 & 200 \\
\hline
\end{tabular}

Tab. 9. Definisane granice NOx emisije u Švajcarskoj [10]

Tab. 9. Defined limits of NOx emissions in Switzerland [10]

\begin{tabular}{|c|c|c|}
\hline Kapacitet/Power, $\mathrm{MW}_{\text {th }}$ & Ref. $\mathrm{O}_{2} \%_{\mathrm{vol}}$ & $\mathrm{NO}_{\mathrm{x}}, \mathrm{mgNO}_{2} / \mathrm{m}^{3}{ }_{\mathrm{o}}$ \\
\hline $0.07-1$ & 13 & $250^{1}$ \\
\hline $1-10$ & 11 & $250^{1}$ \\
\hline$>10$ & 11 & 150 \\
\hline
\end{tabular}




\subsection{0. Španija}

U Španiji ne postoje nacionalna ograničenja emisije za mala i srednja postrojenja za sagorevanje biomase. Kraljevski dekret 430/2004 utvrđuje GVE za postrojenja za sagorevanje biomase (velika >50 MW), u skladu sa LCP. Ministarstvo industrije, turizma i trgovine je izdalo dokument "Tehnički vodič za kotlove na biomasu za grejne instalacije u zgradama", što ukazuje da produkti sagorevanja u ovim instalacijama moraju biti u skladu sa ekološkim zahtevima utvrđenim od strane nacionalnih, regionalnih i lokalnih organa vlasti, u skladu sa standardom EN 303-5 za specificirane granične vrednosti. Potonji, međutim, ne definiše NOx granice, već samo granice emisija za CO, OGC i čestica.

\subsection{Velika Britanija}

Direktiva - Integrisano sprečavanje i kontrola zagađenja (IPPC) je regulatorni sistem implementiran u Velikoj Britaniji koji koristi integrisani pristup za kontrolu ekoloških uticaja industrijske aktivnosti. Da bi dobili dozvolu, investitori moraju da dokažu da je predložena tehnologija BAT za njihovo postrojenje, i da ispunjavaju i druge specifične uslove, uzimajući u obzir relevantne lokalne faktore. Suština BAT je da izabrana tehnologija sa stanovišta zaštite životne sredine je ona kojom se postiže odgovarajuća ravnoteža dobiti između životne sredine i troškova nastalih od strane investitora. Međutim, bez obzira na troškove investicije, ne može se dozvoliti instaliranje postrojenja ukoliko bi rad istog prouzrokovao značajno zagađenje.

\section{ANALIZA GRANIČNIH EMISIJA NOx U SRBIJI}

Granična vrednost emisije azotnih oksida (NOx) za Republiku Srbiju izražene kao $\mathrm{NO}_{2}$ prikazane su u Tab. $10 \mathrm{i}$ definišu se u skladu sa Pravilnikom o graničnim vrednostima emisije zagađivača vazduha [11].

\section{ZAKLJUČAK}

Na osnovu predstavljenih nacionalnih GVE NOx u nekim evropskim zemljama, može se zaključiti da su uglavnom velika i srednja postrojenja podvrgnuta strogim propisima emisije. Izuzetak su zemlje kao što su Austrija, Nemačka, Belgija i Norveška, koje definišu GVE za postrojenja manja od $1 \mathrm{MW}$. Srpska Uredba o GVE zagađivača vazduha kojom se definišu dozvoljene vrednosti emisije jasno regulišu GVE pri sagorevanju čvrste biomase, dok to nije slučaj sa tečnim gorivima. Naime, nigde nije izričito rečeno da tečna goriva mogu biti porekla od biomase, dok se biogas može svrstati u kategoriju "gasova osim prirodnog gasa". Dozvoljene GVE iz velikih i srednjih postrojenja za sagorevanje biomase su uglavnom usklađene sa regulatornim standardima u navedenim evropskim zemljama. Prema vrednostima ovog pravilnika, Srbija je jedna od onih sa strožim ograničenjima po pitanju emisije NOx pri sagorevanje biomase u malim postrojenjima. Treba napomenuti da Uredba ne definiše GVE NOx za sagorevanje biomase koja nije od drvne prirode, što se može smatrati propustom, posebno kada se uzme u obzir da $63 \%$ 
raspoloživih resursa biomase u Srbiji je agro biomasa. Poljoprivredna biomasa se odlikuje visokim sadržajem azota zbog svog intenzivnog đubrenja, kao i činjenice da ista služi za ishranu ljudi i stoke zbog izrazitog sadržaja proteina.

Tab. 10. Granične vrednosti emisije azotnih oksida u Republici Srbiji

Tab. 10. Limited emissions values of nitrogen oxides in the Republic of Serbia

\begin{tabular}{|c|c|c|c|c|}
\hline $\begin{array}{l}\text { Veličina } \\
\text { Plants }\end{array}$ & $\begin{array}{c}\text { Kapacitet } \\
\text { Power, } \mathrm{MW}_{\text {th }}\end{array}$ & $\begin{array}{l}\text { Gorivo } \\
\text { Fuel }\end{array}$ & $\begin{array}{c}\text { Ref. } \mathrm{O}_{2} \\
\%_{\text {vol }}\end{array}$ & $\begin{array}{c}\mathrm{NO}_{\mathrm{x}} \\
\mathrm{mg} / \mathrm{m}_{\mathrm{o}}^{3}\end{array}$ \\
\hline \multirow{7}{*}{$\begin{array}{l}\text { Velika } \\
\text { Large }\end{array}$} & $50-100$ & \multirow{3}{*}{ Čvrsta biomasa } & \multirow{3}{*}{6} & 400 \\
\hline & $100-300$ & & & 300 \\
\hline & $>300$ & & & 200 \\
\hline & $50-100$ & \multirow{3}{*}{ Tečna goriva } & \multirow{3}{*}{3} & 400 \\
\hline & $100-300$ & & & 200 \\
\hline & $>300$ & & & 200 \\
\hline & $>50$ & Gasovi različiti od prirodnog gasa & 3 & 200 \\
\hline \multirow{4}{*}{$\begin{array}{l}\text { Srednja } \\
\text { Medium }\end{array}$} & $1-50$ & \multirow[t]{2}{*}{ Drvo i drvni otpatci } & \multirow[t]{2}{*}{11} & 250 \\
\hline & $1-50$ (SFS) & & & 300 \\
\hline & $5-50$ & Tečna goriva & 3 & 350 \\
\hline & $10-50$ & Gasovi različiti od prirodnog gasa & 3 & 200 \\
\hline \multirow{4}{*}{$\begin{array}{l}\text { Mala } \\
\text { Small }\end{array}$} & $0.1-1$ & $\begin{array}{l}\text { Druga čvrsta goriva različita od uglja i } \\
\text { briketa od uglja i koksa }\end{array}$ & 13 & 250 \\
\hline & \multirow{3}{*}{$<5$} & $\begin{array}{l}\text { Postrojenja sa temperaturom vode } \\
<110^{\circ} \mathrm{C} \text { i nadpritiskom }<0.05 \mathrm{MPa}\end{array}$ & \multirow{3}{*}{3} & 100 \\
\hline & & $\begin{array}{l}\text { Postrojenja sa temperaturom vode } \\
>110^{\circ} \mathrm{C} \text { i }<210^{\circ} \mathrm{C} \text { i nadpritiskom }>0.05 \\
\mathrm{MPa} \text { i }<1.8 \mathrm{MPa}\end{array}$ & & 200 \\
\hline & & $\begin{array}{l}\text { Postrojenja } \mathrm{sa} \text { temperaturom } \\
>210^{\circ} \mathrm{C} \text { i nadpritiskom }>1.8 \mathrm{MPa}\end{array}$ & & 250 \\
\hline
\end{tabular}

Visok sadržaj proteina implicira i visok sadržaj azota. Uzimajući u obzir značajne rezerve agro biomase i činjenicu da se, po pravilu, pri njenom sagorevanju emituje veća količina NOx oksida, kao i zbog činjenice da je za mala postrojenja uvođenje sistema sa sekundarnim merama denitrifikacije obično ekonomski neisplativo, neophodno je, da se definišu blaža ograničenja emisije za sagorevanje biomase ove vrste. U tom smislu, korisno je ugledati se na praksu i iskustva razvijenih agrarnih zemalja kao što su Danska, Velika Britanija ili Nemačka.

\section{LITERATURA}

[1] Directive 2001/80/EC, Council Directive 94/66/EC

[2] Directive 2000/76/EC

[3] MILJØSTYRELSEN (2001). Luftvejledningen, Begrænsning af luftforurening fra virksomheder, Miljø-og Energiministeriet, København, National guideline for emission limits issued by the Danish Environmental Agency, Copenhagen. 
[4] Van Loo, S., Babu S, Baxter L. (2002). Workshop on biomass cofiring, organized by IEA Bioenergy. Amsterdam, the Netherlands.

[5] Erste Verordnung zur Durchführung des Bundes-Immissionsschutzgesetzes (Verordnung über kleine undmittlere Feuerungsanlagen - 1.BImSchV), 26.01.2010.

[6] Technical Instructions on Air Quality Control - TA Luft, of 24 July 2002, http://www.bmub.bund.de/fileadmin/bmuimport/files/pdfs/allgemein/application/pdf/t aluft_engl.pdf

[7] INFOMIL (2006). Wetswegwijzer bio-energie, available at www.infomil.nl

[8] Directive 2008/1/ECof the European Parliament and of the Council of 15 January 2008 concerning Integrated Pollution Prevention and Control.

[9] http://www.miljodirektoratet.no/no/Regelverk/Forskrifter/Regulations-relating-topollution-control-Pollution-Regulations/

[10] Jansen U. (2006). Aktionsplan Feinstaub des Bundes im Bereich Holzfeuerungen und verschärfte Emissionsgrenzwerte. In Feinstaubminderung und Stromerzeugung im Rahmen der zukünftigen Energieversorgung, 9. Holzenergie-Symposium, 20 October, ETH Zürich, Zürich, Verenum, Zürichund Bundesamt für Energie, Bern.

[11] Regulationon emission limit valuesof air pollutants. (Official Gazette of RS, No. 71/2010, 6/2011- correction, 2010/11)

\section{ANALYSIS OF PRESCRIPED LIMITS OF NOX EMISSIONS FROM BIOMASS COMBUSTION IN SELECTED EUROPEAN COUNTRIES AND IN SERBIA}

Milica Mladenović, Stevan Nemoda, Milijana Paprika, Ana Marinković,'Branislav Repić

\section{SUMMARY}

Aligning the need to preserve the environment and the growing energy needs of modern society promotes the use of biomass as a replacement for fossil fuels and viable option to mitigate greenhouse gas emissions. Besides a number of advantages of using the biomass for energy purposes, there are certain disadvantages, one of which is possible relatively high level of NOx emissions during the combustion of biomass. Control of NOx emissions emitted during biomass combustion is becoming increasingly important because of the technical challenge of introducing stricter emission limits. This paper provides an overview and analysis of national standards related to NOx emissions, as well as legal norms and experience some of the selected European countries. It is recommended that the local regulations relating to the NOx emission, specifically define the boundaries in the case of agro biomass combustion, due to its availability and expressed a high nitrogen content.

Keywords: Biomass, combustion, NOx emission, analysis.

Napomena: Rad predstavlja deo istraživanja na projektu „Razvoj i unapređenje tehnologija za energetski efikasno korišćenje više formi poljoprivredne i šumske biomase na ekološki prihvatljiv način, uz mogućnost kogeneracije“ (III42011) koje finansira Ministarstvo prosvete, nauke i tehnološkog razvoja Republike Srbije.

Primljeno: 17. 02. 2016. god.

Prihvaćeno: 08. 03. 2016. god. 